\title{
Evaluation of the Dispersion of Nitrogen Dioxide and Carbon Monoxide in the Indoor Café - Case Study
}

\author{
Ammar A. Al-Sultan ${ }^{1 *}$, Ghufran F. Jumaah', Faris H. Al-Ani' \\ 1 Civil Engineering Department, University of Technology, Baghdad, Iraq \\ * Corresponding author's e-mail: 40321@uotechnology.edu.iq
}

\begin{abstract}
A popularity café in Baghdad city was chosen to measure the dispersion of nitrogen dioxide $\left(\mathrm{NO}_{2}\right)$ and carbon monoxide (CO) as examples of the Indoor Air Pollutants (IAPs) which are considered a significant environmental problem. The aims of this research were, firstly, to measure the variation of $\mathrm{NO}_{2}$ and $\mathrm{CO}$ concentrations; secondly, to examine the effect of the seasonal variation of indoor temperature $\left({ }^{\circ} \mathrm{C}\right)$ and relative humidity $(\%)$ on the dispersion of both $\mathrm{NO}_{2}$ and $\mathrm{CO}$ and finally to compare the results with those of the global standards. The volume of café was about $360 \mathrm{~m}^{3}$ and the number of smokers was about 25-35 smoker/day. This work was divided into two parts where the first part includes the experimental work which comprised the measurement of $\mathrm{NO}_{2}$ and $\mathrm{CO}$ by GIGs devices. It was lasted about five months commencing from November 2017 to March 2018 and the readings were taken during two intervals at partial time and during peak time. The second part includes the analysis of obtained results and compared the results of those of the global standards for the Indoor Air Quality suggested by WHO, EPA, and European criteria in order to achieve the goals of this work. The results from this research have highlighted a clear increase in the concentrations of $\mathrm{NO}_{2}$ and $\mathrm{CO}$ along with the growing numbers of smokers. Furthermore, the concentrations of $\mathrm{NO}_{2}$ and $\mathrm{CO}$ were close to some global standard values of short-term exposure at peak time.
\end{abstract}

Keywords: indoor air pollutants, nitrogen dioxide, carbon monoxide, global standard, smokers

\section{INTRODUCTION}

Currently, the indoor air pollution is the most significant aspect in the environmental philosophy. As the years progressed, man constructed buildings to shield himself from the components, intended to keep out the rain and snow, warm himself in the winter and cool in the mid-year. People usually live, work and spend up to 90 percent of their time indoors. As opposed to holding natural risks under control, the man found himself inside in a substance having contaminants that may even hurt him (Burroughs \& Hansen, 2011). Buildings do not generally provide protection to the inhabitants against being subjected to the contamination. Just the opposite, the molds, parasites, and harmful gases caught or developing within buildings may greatly surpass those outside. By protecting ourselves from the outdoor conditions, we have made an inside domain with a radically new arrangement of issues (Burroughs \& Hansen, 2011). It is perceived that the introduction to air pollutants found indoors impacts a part of human health. In the developed world, a noteworthy extent for our time will be used indoors, the place where defenseless individuals such as, for example, adolescent kids and the elderly could reside for up to $100 \%$ of their time. The presentation focuses on fluctuations, relying upon a number of variables, including the individuals' conduct technique. Moreover, activities, pollutant sources, and geological area were taken into consideration (Coggins, Semple, \& Hurley, 2013).

\section{Problematic overview}

In Iraq, the cafes, which are not subjected to the control of health legislation on the one hand, and are characterized by the absence of engineering design standards from the other side, become 
widespread. It is important for researchers to study the prevalence of the indoor air pollutants (IAPs) and assess the environmental impact of the coffee shops. The list of the issue or IAPs is long, tobacco smoke alone is known to contain 4,700 synthetic mixes, including a few that appear to be exceedingly lethal in creature tests, and 43 presumed cancer-causing mixes (EPA, 2017b; Nadadur \& Hollingsworth, 2015). This examination by EPA who published a white paper with a specific spotlight on the smoke or "environmental tobacco smoke" (ETS) (EPA, 2017b). Notwithstanding setting up ETS as a potential cancer-causing agent and an indoor contaminant of worry for youthful and kids, the report incited the proposed OSHA decision of ' 94 and the resulting tobacco case and nearby jurisdictional controls. The ruling met with negative comments and was never promulgated. However, building owners united with local authorities and reacted with self-regulation and generally banned smoking in public spaces. Similarly, as a result, ETS may be longer be such a significant indoor contaminant to raise concerns (Burroughs \& Hansen, 2011; EPA, 2017b).

\section{Dispersion of $\mathrm{NO}_{2}$ and $\mathrm{CO}$}

The two most common oxides of nitrogen are nitrogen dioxide $\left(\mathrm{NO}_{2}\right)$ and nitric oxide (NO). Both are dangerous gases with $\mathrm{NO}_{2}$ being a very receptive and destructive oxidant (EPA, 2017c). According to EPA, no standards have been settled upon for NOx in the indoor air (EPA, 2017c). Moreover, ASHRAE and the US-EPA National Ambient Air Quality Standards list $0.053 \mathrm{ppm}$ as the average 24-hour limit for $\mathrm{NO}_{2}$ in the outdoor air (EPA, 2017c). WHO has reported a rationale of the indoor $\mathrm{NO}_{2}$ concentration. As an air pollutant, $\mathrm{NO}_{2}$ has different parts, which are regularly troublesome or in some cases difficult to isolate from each other (WHO, 2005). Animal and human exploratory examinations show that $\mathrm{NO}_{2}$, at the concentrations surpassing $200 \mu \mathrm{g} / \mathrm{m}^{3}$ or 0.134 ppm for 1-hour mean, is a harmful gas with huge impacts on wellbeing. The animal toxicological examinations additionally proposed that long haul introduction to $\mathrm{NO}_{2}$ at elevated the concentrations has unfavorable impact (WHO, 2005).

One the other hand, carbon monoxide (CO) is an odorless, colorless and extremely toxic gas. Since it is difficult to see, taste or notice, CO can kill people before they realize it is present (EPA, 2017a; Nadadur \& Hollingsworth, 2015). The impacts of CO introduction can fluctuate enormously from individual to another contingent upon age, general wellbeing and the focus and length of exposure (EPA, 2017a).

There are many standards that limited the indoor CO concentration. The Occupational Safety and Health Administration (OSHA) permissible exposure limit (PEL) for carbon monoxide to be $50 \mathrm{ppm}$ parts of air $\left(55 \mu \mathrm{g} / \mathrm{m}^{3}\right)$ as an 8 -hour time-weighted average (TWA) concentration (EPA, 2017a).

The National Institute for Occupational Safety and Health (NIOSH) has established a recommended exposure limit (REL) for carbon monoxide of $35 \mathrm{ppm}$ or $40 \mu \mathrm{g} / \mathrm{m}^{3}$ as an 8 -hour TWA and $200 \mathrm{ppm}\left(229 \mu \mathrm{g} / \mathrm{m}^{3}\right)$ as the upper limit [NIOSH 1992]. The NIOSH limit is based on the risk of cardiovascular effects (EPA, 2017a). [ACGIH TLV] The American Conference of Governmental Industrial Hygienists (ACGIH) has assigned carbon monoxide a threshold limit value (TLV) of $25 \mathrm{ppm}\left(29 \mu \mathrm{g} / \mathrm{m}^{3}\right)$ as a TWA for a normal 8-hour workday and a 40-hour workweek [ACGIH 1994, p. 15].

Additionally, ACGIH limit is based on the risk of elevated carboxyhemoglobin levels [ACGIH 1991, p. 229] (EPA, 2017a). On the other hand, European Commission's Standards Air Quality and Environment has limited the indoor CO concentration to no more than $10 \mathrm{mg} / \mathrm{m}^{3}$ for maximum daily 8-hours exposure (Commission, 2010).

\section{Indoor air pollutants}

Upwards from claiming 900 air pollutants had to be identified in the indoor household environment. The factors such as nitrogen dioxide $\left(\mathrm{NO}_{2}\right)$, particulate matter $\left(\mathrm{PM}_{2.5}, \mathrm{PM}_{10}\right)$, carbon monoxide (CO) and polycyclic aromatic hydrocarbons (PAHs) are among some of the priority pollutants known to affect health (Europe, 2000; WHO, 2005). The studies on IAP from the fuel used in homes showed that elevated levels of PM, $\mathrm{CO}, \mathrm{NO}_{2}$, and PAHs are associated with the use of fuels or the presence of a smoker in the home. Certain pollutants are more dominant depending on the type of used fuel. Increased levels of $\mathrm{NO}_{2}$ were associated with the use of gas burning appliances (Dennekamp et al., 2010), while the elevated concentrations of $\mathrm{NO}_{2}$ and $\mathrm{CO}$ are the principal pollutants associated with the use of wood-burning appliances (Naeher et al., 2007). 
The relative significance of any single source relies upon the amount of a given contamination it transmits and how perilous those discharges are. For instance, a poorly balanced gas stove can transmit fundamentally more carbon monoxide than one that is legitimately balanced (Nadadur \& Hollingsworth, 2015). A few sources, for example, building materials, furniture and items like deodorizers can discharge poisons persistently. Different sources, identified with exercises like smoking, cleaning, rearranging or doing totters discharge contaminations irregularly. Unvented or malfunctioning machines or improperly utilized items can discharge higher and in some cases hazardous levels of pollutants indoors (EPA, 2017b).

Indoor Air pollution can happen by the following ways (Saha, Kamyotra, \& Khare, 2014):

- High temperature and humidity levels increase the concentrations of some pollutants.

- There are numerous sources of indoor air contamination in any home. These incorporate ignition sources, for example, oil, gas, lamp fuel, coal, wood, and tobacco items; building materials and decorations as various as weakened, asbestos-containing protection, wet or moist cover, and cabinetry or furniture made of certain squeezed wood items; items for family unit cleaning and upkeep, individual care, or leisure activities; cooling frameworks and humidification gadgets; and open-air sources, for example, radon, pesticides, and outside air contamination.

- Outdoor air goes in and out by penetration, characteristic ventilation, and mechanical ventilation. In a procedure known as penetration, wind streams enter the house through openings, joints, and breaks in dividers, floors, and roofs, and around windows and entryways. In regular ventilation, the air travels through opened windows and entryways. The air development related to infiltration and normal ventilation is caused by the air temperature differences amongst inside and outside and by the wind.

- High pollutant concentrations can stay in the indoor air for significant periods of time.

- The pollution can originate from cleaning articles and housekeeping.

\section{Classification of indoor air pollutants}

Indoor environment contaminants into classified by three groups (Saha et al., 2014; Spengler, McCarthy, \& Samet, 2001) which are:
- Biological presentation: Allergens or microbiological;

- Chemical presentation: Dust, pressurized canned products or vapors;

- Physical presentation: Acoustic condition, mugginess, air development, warm conditions.

\section{Research objectives}

This study was set out to achieve the following objectives:

- Measurement of $\mathrm{NO}_{2}$ and $\mathrm{CO}$ levels in the café under study.

- Studying the effect of seasonal variation of both temperature $\left({ }^{\circ} \mathrm{C}\right)$ and relative humidity (\%) on the dispersion of $\mathrm{NO}_{2}$ and $\mathrm{CO}$.

- Discussing the results with those of the global standards.

\section{EXPERIMENTAL WORK}

In this work, we divided the research into two parts. The first part included the experimental work which consisted of measurement of $\mathrm{NO}_{2}$ and $\mathrm{CO}$ by using GIGs devices. It lasted about five months from November 2017 to March 2018. Firstly, calibration for the GIGs devices was done in the Division of the quality control and occupational safety, Ministry of Industry and Minerals. Additionally, the experimental work has focused on the following tips:

- Selecting a popularity café situated in the AlGazalia sector, Baghdad city where this coffee shop was without ventilation control and no health monitoring as a worst case study.

- The café box volume was about $360 \mathrm{~m}^{3}$.

- The number of customers and smoking customers were about 35-50 per day and the number of hookah users was 25-35 per day which may help to calculate the modeling of the IPAs dispersion.

- Taking the readings of the IAPs in a wide range of variation of time, temperature and $\%$ relative humidity.

GIGs device was used with four gas sensors. It was made in Germany; the principle of its work depends on the sensitivity of gases emitted from the source of pollution, the concentrations of smoke are transformed into an electrical signal that is read in the data-logger as ppm (Figure 1). Moreover, an electronic thermometer and relative humidity measurement device was used to record 
the temperature $\left({ }^{\circ} \mathrm{C}\right)$ and relative humidity $(\%)$ (Figure 2).

The second part includes the analysis of results; hence, the study compared the results with the global standards for the Indoor Air Quality like WHO, EPA, and European Commission criteria in order to achieve the goals of this work.

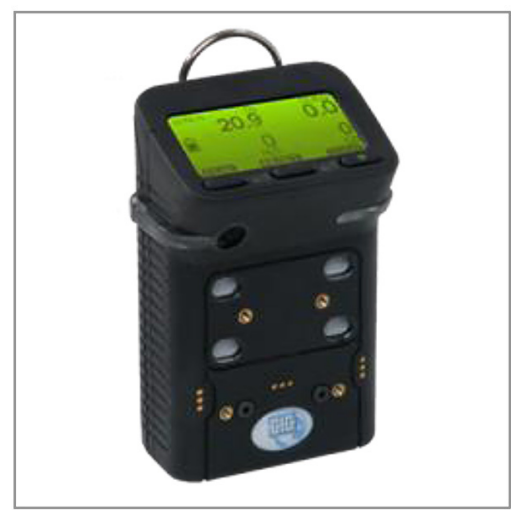

Fig. 1. GIG, IAPs device measurement

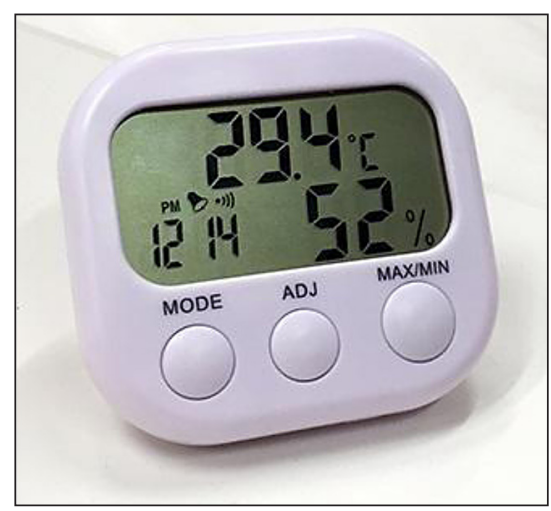

Fig. 2. Electronic thermometer

\section{Point of readings}

Many previous works reported the locations of the reading points, where we noticed the need to take models at points far from oscillation (Hirt \& Cook, 1972). We fixed the sampling point at the height of $(2.0 \mathrm{~m})$ in the center of the hall. This point was the best location, which can take the stable readings of GIG devices as well as the high density of the smoke.

\section{Indoor temperature degree and relative humidity}

Temperature and relative humidity are the most effective parameters that may contribute to the dispersion of the IAPs (Nadadur \& Hollingsworth, 2015; Spengler et al., 2001). Therefore, we recorded a wide range of the readings. In this work, the variation of café temperature and relative humidity was given in the Table 1 .

\section{RESULTS AND DISCUSSIONS}

\section{Variation of nitrogen dioxide with time, temperature, and relative humidity}

Figures 3-5 show the variation of $\mathrm{NO}_{2}$ average concentrations at the partial capacity and peak time capacity of the café for the first, second and third round, respectively. The periods of readings of the first, second, and third round were displayed in the Table 1. From these figures, it seems that there was a marked increase in the concentrations of $\mathrm{NO}_{2}$ along with the growing numbers of smokers.

Figure 3 shows that the variation of $\mathrm{NO}_{2}$ average concentrations for the first round at the partial capacity time was lesser than those of standard, but the concentrations at the peak time were above the standard when the indoor temperature was about $30^{\circ} \mathrm{C}$ and the relative humidity was relatively high (35-37\%).

Figures 4 and 5 represent the variation of $\mathrm{NO}_{2}$ average concentrations for the second and third rounds at the partial capacity time which were lesser than standard while the concentrations at the peak time were close to the standard. The average indoor temperature of the second and third rounds was $25^{\circ} \mathrm{C}$ and the relative humidity was $25 \%$ and $22 \%$, respectively.

These results reflect the increased $\mathrm{NO}_{2}$ concentrations with a growing number of smokers, as well as an increase in the density of smoke in the absence of quality control through the presence of fresh air and ventilation (Daisey,

Table 1. Variation of the temperature and relative humidity during the rounds of sampling

\begin{tabular}{|c|c|c|c|}
\hline Round & Period & Temp. $\left({ }^{\circ} \mathrm{C}\right)$ & Relative humidity $(\%)$ \\
\hline $1^{\text {st }}$ & September14-18, 2017 & 30 & 37 \\
\hline $2^{\text {nd }}$ & March 1-4, 2018 & 25 & 27 \\
\hline $3^{\text {rd }}$ & April 3-6, 2018 & 25 & 22 \\
\hline
\end{tabular}




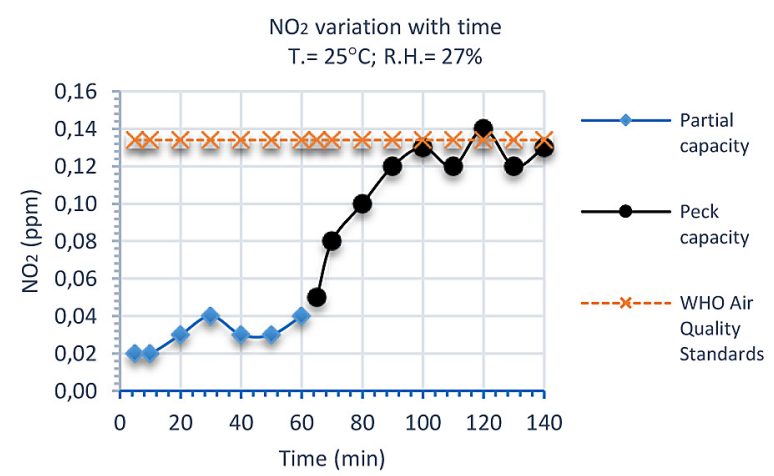

Fig. 3. Variation of $\mathrm{NO}_{2}$ for the $1^{\text {st }}$ round

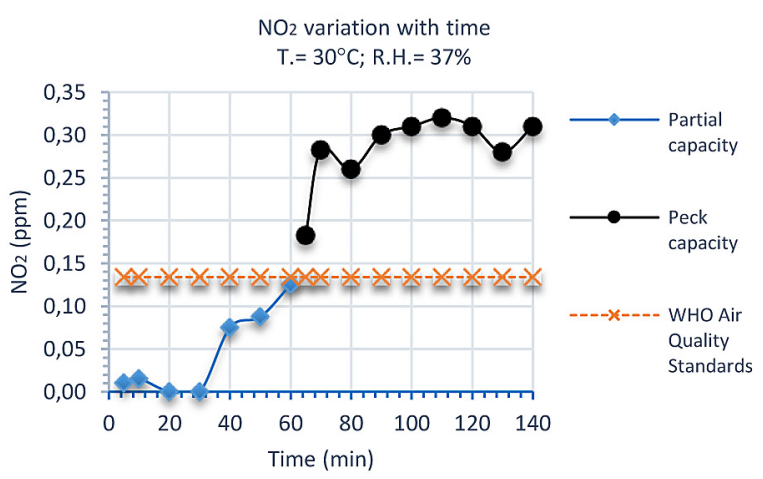

Fig. 4. Variation of $\mathrm{NO}_{2}$ for the $2^{\text {nd }}$ round

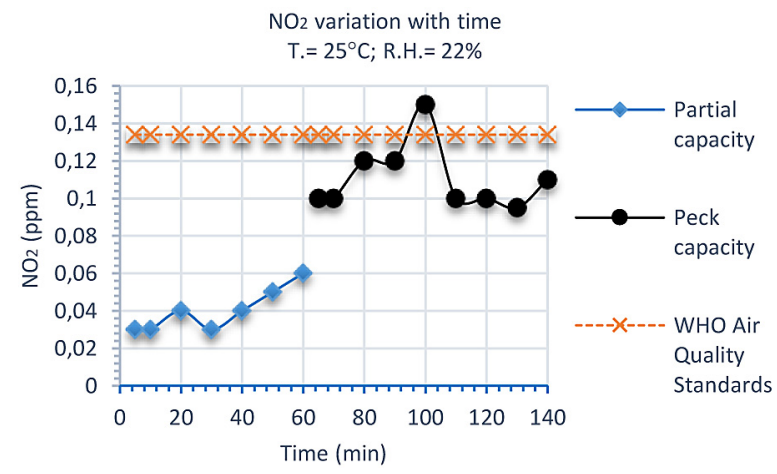

Fig. 5. Variation of $\mathrm{NO}_{2}$ for the $3^{\text {rd }}$ round

Angell, \& Apte, 2003). Another result regards the temperature of the café. High temperatures increased the speed of dispersion and spread of air pollutants. This finding is consistent with the results obtained by other researchers (Fang, Clausen, \& Fanger, 1998; Wainman, J., Lioy, \& Zhang, 2001).

\section{Variation of carbon monoxide with time, temperature, and relative humidity}

Figures from 6 to 8 show the contrast of $\mathrm{CO}$ average concentration with time. It is clear that the effect of increasing the number

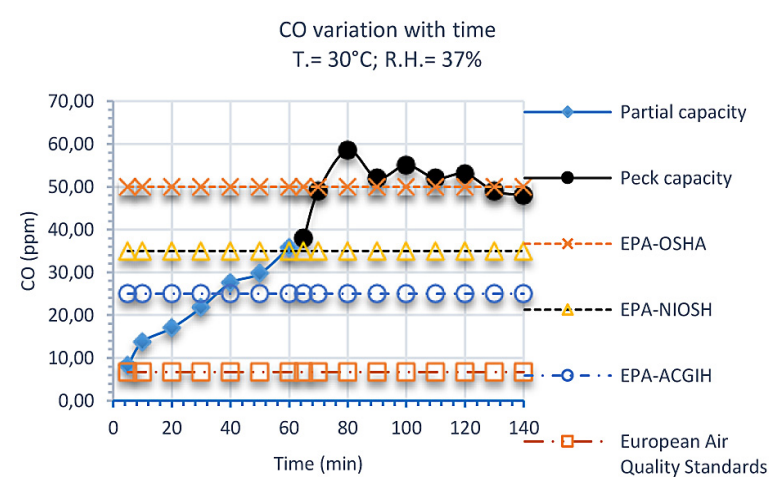

Fig. 6. Variation of $\mathrm{CO}$ for the $1^{\text {st }}$ round

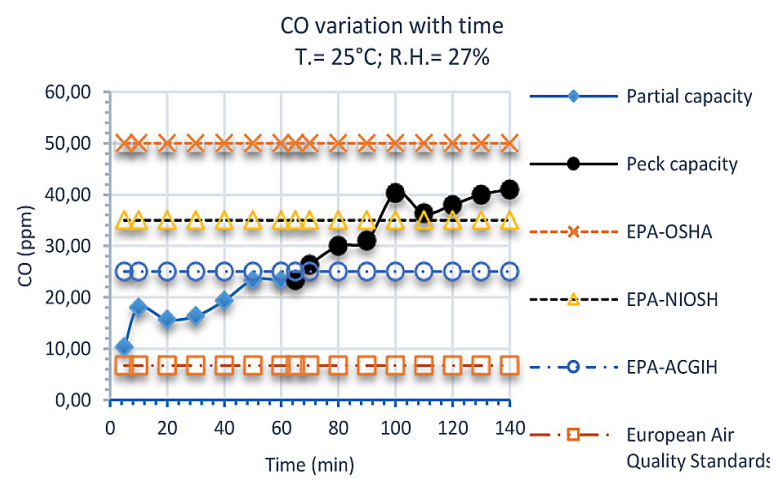

Fig. 7. Variation of $\mathrm{CO}$ for the $2^{\text {nd }}$ round

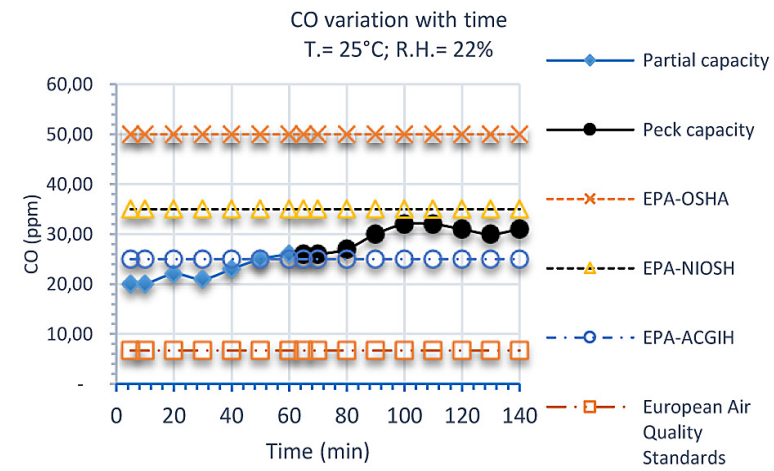

Fig. 8. Variation of $\mathrm{CO}$ for the $3^{\text {rd }}$ round

of smokers, temperature degree, and relative humidity corresponds to the increasing $\mathrm{CO}$ concentration. The explanation is that the increasing number of smokers will lead to greater intensity of the indoor smoke. Additionally, rising temperatures will increase the chance of dividing $\mathrm{CO}_{2}$ into $\mathrm{CO}$ and $\mathrm{O}$. These results were supported in other studies (Fang et al., 1998; Klepeis, Ott, \& Switzer, 1996). Moreover, Figures 6-8 show exceeded CO concentrations in relation to EPA and European standards, and this indicates the hazard of this gas, especially for children and non-adults (Commission, 2010; EPA, 2017a). 


\section{CONCLUSIONS}

The following conclusions may be drawn from this work:

1. A positive relation was found between the increase in $\mathrm{NO}_{2}$ and $\mathrm{CO}$ and a growing number of smokers over time, especially at the peak time.

2. There was an increase in $\mathrm{NO}_{2}$ and $\mathrm{CO}$ associated with the increasing of indoor temperature, as the temperature increases the speed of dispersion of IAPs as well as the chance of fragmentation and molecules becoming relatively unstable are greater.

3. The results indicate a clear effect of relative humidity on the increase the concentrations of the majority of IAPs, where water vapor intensifies emissions, leading to increased concentrations of pollutants.

4. The most striking result emerging from the figures is that inadequate ventilation increases the indoor toxin levels by not providing enough fresh air and sometimes the air pollutants emitted as result of smoking exceed the standard limits.

\section{REFERENCES}

1. Burroughs, H.E., \& Hansen, S.J. 2011. Managing Indoor Air Quality (5th ed.): Taylor \& Francis Ltd.

2. Coggins, M.A., Semple, S., \& Hurley, F. 2013. Indoor Air Pollution and Health, STRIVE Report In (2008-EH-MS-8-S3) (Ed.), (pp. 49). EPA department, Wexford, Ireland

3. Commission, E. 2010. Standards Air Quality Environment

4. Daisey, J.M., Angell, W.J., \& Apte, M.G. 2003. Indoor air quality, ventilation and health symptoms in schools: an analysis of existing information. Indoor Air Quality, 13, 53-64.

5. Dennekamp, M., Akram, M., Abramson, M.J., Tonkin, A., Sim, M.R., Fridman, M., \& Erbas, B. 2010. Outdoor air pollution as a trigger for out-of-hospital cardiac arrests. Epidemiology, 21(4), 494-500.

6. EPA. 2017a. Carbon Monoxide's Impact on Indoor Air Quality, Indoor Air Quality (IAQ), US, EPA (pp. 6).

7. EPA. 2017b. Introduction to Indoor Air Quality Indoor Air Quality (IAQ), Primary Causes of Indoor Air Problems (pp. 2). USA.

8. EPA. 2017c. Nitrogen Dioxide's Impact on Indoor Air Quality. US, EPA.

9. Europe, W.R.O.F. 2000. Air Quality Guidelines. In C. 6.6 (Ed.), Hydrogen sulfide (Second Edition ed.). Copenhagen, Denmark

10. Fang, L., Clausen, G., \& Fanger, P.O. 1998. Impact of Temperature and Humidity on the Perception of Indoor Air Quality. Indoor Air Quality, 8, 80-90.

11. Hirt, C.W., \& Cook, J.L. 1972. Calculating ThreeDimensional Flows around Structures and over Rough Terrain. Journal of Computational Physics, 10, 324-340.

12. Klepeis, N., Ott, W.R., \& Switzer, P. 1996. A Multiple-Smoker Model for Predicting Indoor Air Quality in Public Lounges. Environmental Sciences and Technology, 30, 2813-2820.

13. Nadadur, S.S., \& Hollingsworth, J.W. 2015. Air Pollution and Health Effects. Springer-Verlag London.

14. Naeher, L.P., Brauer, M., Lipsett, M., Zelikoff, J.T., Simpson, C.D., Koenig, J.Q., \& Smith, K.R. (2007). Woodsmoke health effects: a review. Inhalation toxicology, 19(1), 67-106.

15. Saha, D., Kamyotra, S.J., \& Khare, M. 2014. Indoor Air Pollution, Monitoring Guidelines (pp. 19). INDIA Central Pollution Control Board, Ministry Of Environment \& Forests, Govt. Of India, East Arjun Nagar, Delhi 110032.

16. Spengler, J.D., McCarthy, J.F., \& Samet, J.M. 2001. Indoor Air Quality Handbook: McGrawHill, New York.

17. Wainman, T.J., W.C., Lioy, P.J., \& Zhang, J. 2001. Effects of Surface Type and Relative Humidity on the Production and Concentration of Nitrous Acid in a Model Indoor Environment. Environmental Science \& Technology, 35(11), 2200-2206.

18. WHO 2005. WHO Air quality guidelines for particulate matter, ozone, nitrogen dioxide and sulfur dioxide. In: WHO/SDE/PHE/OEH/06.02 (Ed.), Global update 2005 (pp. 22). 